\title{
Características clínicas e citogenéticas de pacientes com síndrome de Down hospitalizados em uma UTI cardiológica pediátrica
}

\author{
Poli, J.H.Z.; Vogt, G.N.; Feltes, I.C.; Sampaio, V.O.; de Sá, D.C.; Rosa, R.F.M.; \\ Apresentador: Jefferson Henrique Zwir Poli
}

\section{Resumo}

Introdução: A síndrome de Down é uma doença genética bastante comum, sendo que representa a principal causa conhecida de cardiopatias congênitas (CCs). Nosso objetivo foi verificar a frequência e as características clínicas e citogenéticas de pacientes com síndrome de Down (SD) e CC que internaram em uma Unidade de Tratamento Intensivo (UTI) cardiológica pediátrica. Método: avaliou-se uma coorte prospectiva e consecutiva de pacientes hospitalizados pela primeira vez por CC na UTI Cardiológica do Hospital da Criança Santo Antônio, durante o período de 1 ano. Para cada paciente foi aplicado um protocolo clínico padrão, com realização de ultrassom abdominal e exame de cariótipo. Resultados: em uma amostra de 207 pacientes, o cariótipo pôde ser realizado com sucesso em 204. Alterações cromossômicas foram verificadas em 29 indivíduos: 24 deles (12\%) com SD (23 por trissomia livre do cromossomo 21 e 1 por isocromossomo 21 q). As principais CCs observadas nestes pacientes foram os defeitos septais $(\mathrm{N}=18)$, em especial o defeito de septo atrioventricular (DSAV), verificado em metade dos casos. Por outro lado, a SD foi responsável por 55\% do total de casos de DSAV da amostra, sendo a associação deste defeito com a SD estatisticamente significante. Não houve diferença na frequência de alterações detectadas ao ultrassom abdominal e no tempo de internação entre pacientes com SD e cariótipo normal. Idade materna avançada foi mais comum entre os pacientes com SD. Conclusões: a frequência de SD encontrada e os tipos de alterações cromossômicas identificadas foram concordantes com a literatura. Em nossa série, os pacientes com SD apresentaram uma boa evolução, similar aos pacientes com cariótipo normal, de forma concordante com a descrita em outros trabalhos.

\section{Referência:}

Poli, J.H.Z.; Vogt, G.N.; Feltes, I.C.; Sampaio, V.O.; de Sá, D.C.; Rosa, R.F.M.; Características clínicas e citogenéticas de pacientes com síndrome de Down hospitalizados em uma UTI cardiológica pediátrica. In: Il Congresso Brasileiro de Medicina Hospitalar - II CBMH [= Blucher Medical Proceedings, vol.1, num.5] São Paulo: Editora Blucher, 2014. p.77 DOI 10.5151/medpro-II-cbmh-074 